\title{
Diagnostic Aspects of Paracoccidioidomycosis
}

\author{
Rosely Maria Zancope-Oliveira • Claudia Vera Pizzini • Mauro de Medeiros Muniz • \\ Antonio Carlos Francesconi do Valle • Rodrigo Almeida-Paes
}

Published online: 16 May 2014

(C) Springer International Publishing AG 2014

\begin{abstract}
The gold standard for the diagnosis of paracoccidioidomycosis is direct examination and culture; however, serologic, histopathologic, and molecular approaches have been recently adopted for the diagnosis of this mycosis. Few molecular methods have been applied to the diagnosis of paracoccidioidomycosis to detect Paracoccidioides spp. DNA from clinical specimens, and to identify the same fungi in culture. In this review, we focus on the current diagnosis of the paracoccidioidomycosis, and discuss the current molecular tools applied to the diagnosis and identification of the Paracoccidioides complex species.
\end{abstract}

Keywords Paracoccidioidomycosis · Paracoccidioides spp · Diagnose $\cdot$ Mycology, serology, molecular techniques .

Tropical mycosis $\cdot$ Tropical medicine $\cdot$ Review

\section{Introduction}

The endemic mycosis paracoccidioidomycosis (PCM) has the genus Paracoccidioides as its etiologic agent, and occurs as an active disease in up to $2 \%$ of infected individuals [1]. Phylogenetic and population studies of Paracoccidioides species indicate that the genus comprises at least four phylogenetic lineages: S1 (species 1 from Brazil, Venezuela, Peru, Paraguay, and Argentina), PS2 (phylogenetic species from Brazil

R. M. Zancope-Oliveira $(\bowtie) \cdot$ C. V. Pizzini ·

M. de Medeiros Muniz $\cdot$ R. Almeida-Paes

Setor de Imunodiagnóstico do Laboratório de Micologia do Instituto de Pesquisa Clínica Evandro Chagas, Fundação Oswaldo Cruz. Av. Brasil 4365, Manguinhos, Rio de Janeiro 22045-900, Brazil

e-mail: rosely.zancope@ipec.fiocruz.br

\section{A. C. F. do Valle}

Laboratório de Pesquisa Clínica em Dermatologia Infecciosa, Instituto de Pesquisa Clínica Evandro Chagas, Fundação Oswaldo Cruz, Rio de Janeiro, RJ, Brazil and Venezuela), PS3 (phylogenetic species from Colombia), all three of which are included in the Paracoccidioides brasiliensis species [2,3], and $P b 01$, now proposed to be P. lutzii $[4 \bullet \cdot]$. The disease is one of the most prevalent systemic mycoses in Latin America [5], and some cases have been reported outside of the American continent, both in individuals from endemic areas and in returning travelers from those regions [6]. Despite the large number of cases frequently diagnosed, the exact epidemiology of PCM is not known since there is no compulsory notification of identified cases in many countries. Due to the lack of available data, PCM was recently added to the list of neglected diseases [7].

PCM is a typical occupational infection of farmers and outdoors workers, preferentially affecting men, mostly in the third and fourth decades of life. As a rule, P. brasiliensis infection is acquired by the inhalation of airborne fungal particles after soil is turned over; the conidia can easily reach the alveoli when inhaled, and a lung-lymph node primary complex is developed. These early lesions may remain silent for many years and, in a manner similar to tuberculosis and other systemic mycoses, they may at any time progress in the lungs or disseminate by the lymphohematogenic route.

Pathogenic fungi of the genus Paracoccidioides are dimorphic in the environment or when cultured in the laboratory at 25 $30^{\circ} \mathrm{C}$. In the filamentous form, the fungus grows slowly, with a wide variety of colonial morphologies presenting as forms ranging from a glabrous leathery, brownish, flat colony with a few tufts of aerial mycelium to a wrinkled, folded, floccose form, to velvety, white, pink, and beige forms. Microscopically, a variety of conidia is seen, none of which is characteristic of the species. In contrast, the parasitic phase and the yeast phase of Paracoccidioides that develops when the fungus is cultured in appropriate culture media at $35-37^{\circ} \mathrm{C}$, present $2-30 \mu \mathrm{m}$ or more yeast cells, which may be oval or irregular shapes with one or more buds [8]. Macroscopically, colonies of Paracoccidioides have a yellowish-beige color and a creamy texture. 
Mycoses can be challenging to diagnose, and accurate interpretation of laboratory data is important to ensure appropriate treatment. Although the clinical manifestations of PCM are well-described, the diagnosis of this mycosis cannot be based on clinical information alone because the symptoms of PCM overlap with those of other diseases.

PCM is classically diagnosed by correlation of clinical, epidemiologic, and laboratory data. To confirm the diagnosis, laboratory examinations must be performed. Typical laboratory analyses involved in PCM diagnosis include microscopic examination and cultures of clinical specimens, such as skin biopsies or pus, sputum, urine, blood, synovial and cerebrospinal fluids, can be analyzed depending on the affected organs or systems. Currently, there are additional diagnostic tools available for diagnosis of PCM to supplement culture and microscopic examination. These laboratory tests have a rapid turnaround time and reasonable specificity and sensitivity. For instance, serologic techniques involving antibody and antigen detection have been developed using different methodologies. Molecular methods to detect Paracoccidioides DNA in clinical specimens, including tissue fragments, are also being studied in several laboratories to facilitate rapid diagnosis of the infection. The accuracy of routine diagnostic tests applied for PCM was recently reviewed in a university hospital in Brazil, demonstrating that the association of conventional tests with serologic tests is sufficient to establish laboratory diagnosis of PCM [9].

The following sections focus on these applications for diagnosis of PCM. Some of the well-established clinical and laboratorial diagnoses are discussed and current conventional diagnostic tools are reviewed. Additionally, we outline the development of novel molecular methods and discuss their relative merits.

\section{Clinical Diagnosis}

PCM has clinical manifestations that require differentiation from tuberculosis, Hodgkin disease, several systemic and subcutaneous mycoses, and squamous cell carcinoma [10]. The primary pulmonary infection is usually subclinical, and individuals may never develop clinical signs. A small percentage of patients present with clinical symptoms, most of whom have lung involvement [11].

The most common form of this infection in adults is the chronic multifocal form, in which there is dissemination to the lungs, lymph nodes, skin, and mucosae. Cough, dyspnea, weight loss, and cutaneous and mucosal lesions are the major complaints reported by patients with PCM. Chest X-rays reveal diffuse reticulonodular infiltrates, which are more evident in the upper lobes. The acute form usually presents as lymph node enlargement and cutaneous lesions, with digestive and osteoarticular symptoms. Other manifestations include anemia, fever, and weight loss, with the overall health of patients deteriorating rapidly. Pulmonary involvement in the acute form is rare. The initial investigation should include the following non-specific tests: chest $\mathrm{X}$-ray, blood cell counts, liver function tests, urea, creatinine, sodium, and potassium [12].

\section{Conventional Diagnosis}

Depending on which clinical specimen is sent to the mycological laboratory for diagnosis, some procedures take place before microscopic and culture analysis. Skin biopsies should be sent for culture under sterile physiological saline solution. Water and formaldehyde are not suitable as transport liquids, since they interfere with the microbiological tests. However, formaldehyde must be used when sending a tissue sample for histopathological examination. In the laboratory, skin biopsies have to be triturated using surgical scissors. Grinding them with mortar and pestle must be avoided since this procedure can destroy some fungal structures that can be present on the material. On the other hand, pus from ulcerated lesions or skin scrapings do not need any previous treatment, and can be analyzed after sample collection. Liquid samples such as sputum, bronchoalveolar lavage, and cerebrospinal fluid must be centrifuged and the supernatant discarded before mycological examination [13].

Direct microscopic examination of the specimens is typically made with $10 \%$ potassium hydroxide $(\mathrm{NaOH})$ or $4 \%$ sodium hydroxide $(\mathrm{KOH})$ in order to detect parasitic multiple budding yeast cells using a light microscope under a 400 $1,000 \times$ magnification. These cells are large $(3-30 \mu \mathrm{m}$ in diameter), round to oval, and multiple buds are attached to the parent cell by narrow connections (see Fig. 1a) [14]. Differentiation between P. brasiliensis and Blastomyces dermatitidis yeast cells is not usually a problem because the endemic areas of the diseases caused by these fungi do not overlap [15]. However, for the diagnosis of imported mycoses, the differentiation is easy because $B$. dermatitidis yeasts present a single bud with a broad connection to the parent cell [14].

Histopathological examination is of great value for the diagnosis of PCM. Although P. brasiliensis yeast cells might be seen routinely using hematoxylin and eosin (H\&E) stain, other stains such as Gomori methenamine silver (GMS), periodic acid-Schiff (PAS), and immunohistochemical staining can be used to enhance detection of fungal elements. Tissues present granuloma formation with multinucleated giant cells, a polymorphonuclear infiltrate, and the pathognomonic "ship's wheel" budding yeast cells [16].

Definitive diagnosis of PCM is based on the isolation and identification of its etiological agent in culture. Isolation of P. brasiliensis can be obtained after spreading the clinical 
Fig. 1 Paracoccidioides brasiliensis yeast cell microscopic morphology: (a) sodium hydroxide $10 \%$ preparation; (b) typical "pilot-wheel" shape stained with lactophenol cotton blue

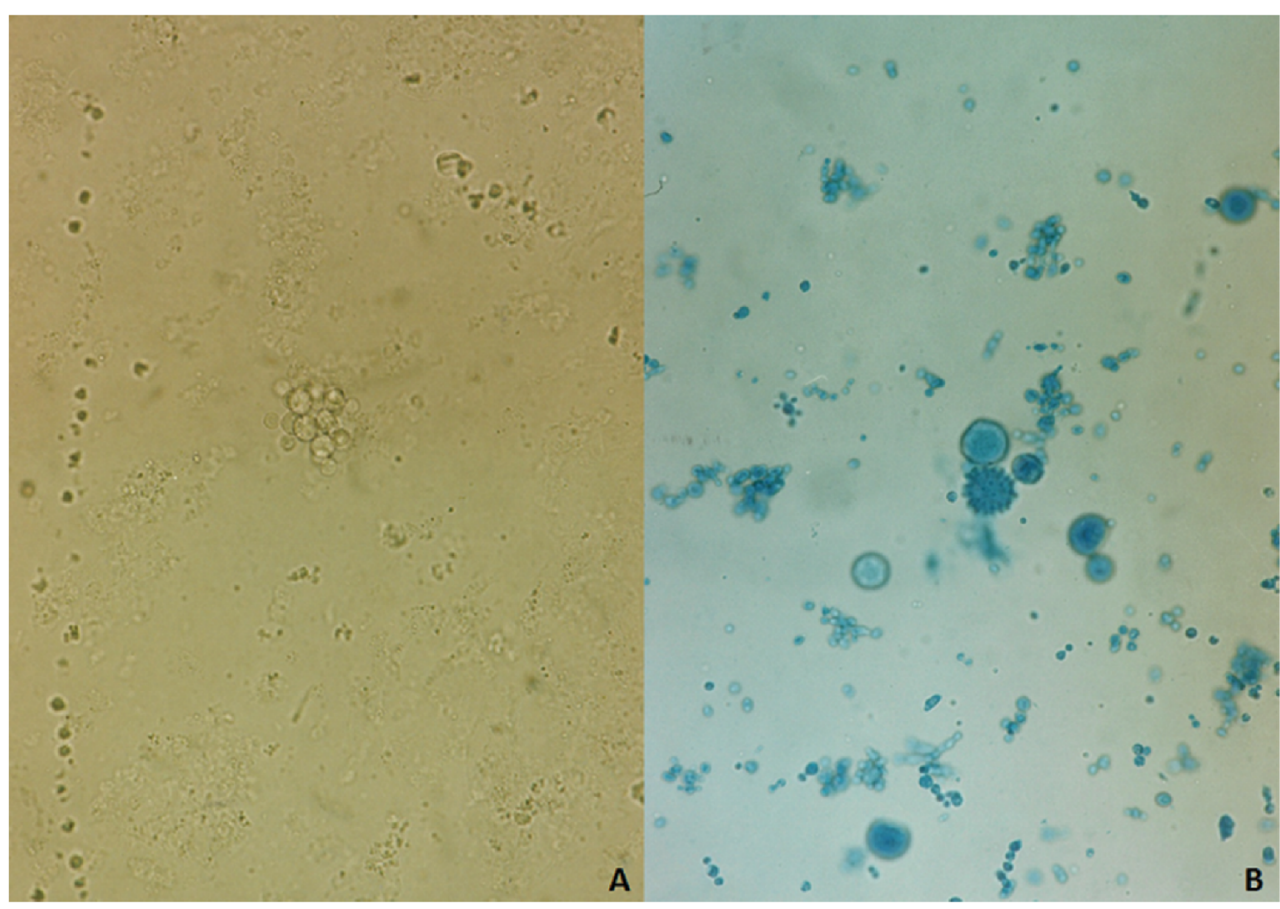

specimens on routinely used Sabouraud Dextrose Agar supplemented with $400 \mathrm{mg} / \mathrm{L}$ of chloramphenicol to avoid bacterial contamination and on cycloheximide-containing media such as Mycosel or Mycobiotic agar. Cycloheximide inhibits growth of several anemophilous fungi that can contaminate cultures from clinical specimens obtained from non-sterile sites; however, this drug does not impair the growth of $P$. brasiliensis [17]. Although $P$. brasiliensis can grow at around body temperature, this is not the optimal temperature for fungal growth. Therefore, to enhance the odds of fungal isolation, cultures must be incubated at $25-30{ }^{\circ} \mathrm{C}$. After $2-$ 3 weeks of incubation, filamentous colonies start to grow. However, some strains require extended incubation for growth. These colonies present a white mycelium that often turns brown after some time and microscopically septate branched hyphae can be observed. Infrequently, a few microconidia are observed along the hyphae [14]. For final identification, conversion to the yeast phase must be performed by subculturing the fungus at $37{ }^{\circ} \mathrm{C}$ in brain heart infusion or Fava-Netto's Agar (proteose peptone $3 \mathrm{~g} / \mathrm{L}$, peptone $10 \mathrm{~g} / \mathrm{L}$, beef extract $5 \mathrm{~g} / \mathrm{L}, \mathrm{NaCl} 5 \mathrm{~g} / \mathrm{L}$, yeast extract $5 \mathrm{~g} / \mathrm{L}$, glucose $4 \%, \mathrm{pH} 7.2$ ). In these media, yeast cells, similar in size and shape to those observed in parasitism, must be observed (see Fig. 1b). If there is no growth of P. brasiliensisresembling fungal colonies after a 6-week incubation period, cultures can be considered negative.

Despite being the gold standard, direct examination requires skilled professionals to read the test, the culture takes a long time, and handling this fungus raises biohazard concerns [18]. In addition, these methods are not enough to differentiate the new cryptic species on the $P$. brasiliensis complex, since the only morphological difference between them is conidial morphology: $P$. lutzii isolates present elongated conidia, while $P$. brasiliensis isolates have short round conidia [19]. Cultures from clinical specimens on routine mycological media usually lack conidial formation.

Recently, a new microdilution method for antifungal susceptibility of $P$. brasiliensis isolates was described. This proposed protocol employs an inoculum concentration of $1 \times 10^{5}$ cells/mL in Müeller-Hinton medium and an incubation temperature of $35-37{ }^{\circ} \mathrm{C}$ for 15 days. This method was able to determine reliable minimal inhibitory concentrations of amphotericin B, itraconazole, ketoconazole, fluconazole, and terbinafine for 22 P. brasiliensis isolates [20•].

\section{Serology}

Serologic techniques are usually simpler than culture and very useful in the diagnosis and follow-up of patients with PCM. The following serologic tests have been used for diagnosing PCM: agar gel immunodiffusion (ID), tube precipitin, complement fixation (CF), counter-immunoelectrophoresis (CIE), immunofluorescence, radioimmunoassay, passive hemagglutination inhibition, immunoenzyme assays, such as ELISA, MELISA, dot blot [18], and inhibition-ELISA [21], and, more recently, the latex agglutination test [22]. These techniques have had considerable advances in the past decades because of the development of innovative detection schemes, identification of relevant $P$. brasiliensis antigens, and increasing use of monoclonal antibody technology for application in immunoassays $[23 \bullet \bullet]$. The literature concerning the serodiagnosis of 
PCM is extensive and diverse, extending back to the first description of a complement reaction by Moses in 1916 [24]. For detailed summaries of the work in this field up to 2011, the reviews by Teles and Martins [18] and Camargo [25] are recommended. However, in the last 3 years some important contributions to this field have been made, and these are discussed in this section.

A range of antigenic preparations, derived both from whole yeast cells and culture filtrate, in their crude and/or purified state, have been applied in the serologic tests, which resulted in high cross-reactivity, one of the most persistent problems found in the serodiagnosis of PCM. Moreover, these antigenic preparations present antigenic variability, making it very difficult to standardize diagnostic techniques in different laboratories [26-]. For these reasons, several groups have been working with pooled crude exoantigens of $P$. brasiliensis in conventional serologic techniques such as ID, CIE, ELISA $[27,28]$, and western blot [29]. Recently, corroborating these findings, Machado et al. [30••] analyzed the impact of cryptic species of $P$. brasiliensis on the PCM immunodiagnosis. The authors emphasize that the use of a single antigen preparation in the conventional serologic tests is not recommended, since a small concentration of glycoprotein gp43, the main $P$. brasiliensis antigen, was found in culture filtrates of $P$. lutzii strains, and the production of this antigen varied between isolates belonging to the same species.

Production of several antigenic preparations has improved sensitivity and specificity of the serologic tests focused on antibody detection. Some purified antigens from $P$. brasiliensis, such as gp 43 , have been widely applied in the immunodiagnosis of PCM. Patients affected by severe PCM forms show high levels of anti-gp43 antibodies, which decrease over the course of disease treatment in most cases $[31,32]$. In fact, $90 \%$ of PCM patients present positive results for gp 43 -based ID assays and around $100 \%$ for immunoblotting assays [32]. The protein p87 [33] has also been considered as a suitable alternative antigen for serologic diagnosis of this mycosis.

Fusion molecules from the genus Paracoccidioides obtained by recombinant technology have been also used as alternative antigens for the immunodiagnosis of PCM. The gene encoding gp43 was the first antigen cloned and expressed as a recombinant fusion protein [34], and it showed high reactivity when evaluated with sera from patients with PCM. McEwen et al. [35] cloned the protein $\mathrm{p} 27(\mathrm{rPb} 27)$, which has been applied to detect immune responses by ELISA [36, 37]. Recently, the utility of $\mathrm{rPb} 27$ and the secreted and surface Mexp antigen was evaluated in an in-house ELISA for detection of the $\operatorname{IgG}$ profile and its subclass levels in 92 serum samples from 54 chronic PCM patients at different points during or after treatment. There was a tendency towards decreasing antibody levels during treatment, but these levels do not clear in most patients after treatment is stopped [38].
Besides gp43 and p27, other recombinant fusion proteins such as heatshock protein (hsp) 60 [39] and hsp70 [40] have been described as an interesting tool for PCM diagnosis. More recently, combined use of $P$. brasiliensis recombinant $\mathrm{rPb} 27$ and $\mathrm{rb} 40$ antigens in an indirect ELISA provided an excellent immunodiagnosis assay for PCM, showing 96 and $100 \%$ sensitivity and specificity, respectively [26 $6^{\circ}$. These data indicate that the use of a multiantigenic preparation is an efficient strategy to improve the sensitivity and specificity of an immunoassay, corroborating data suggested in the early 2000 s [41]. In addition, a synthetic peptide named P2 that mimicked the epitope of the $75 \mathrm{kDa}$ protein of $P$. brasiliensis was recognized in untreated PCM patients' sera from acute and chronic forms of PCM in an ELISA, showing $100 \%$ sensitivity and $94.59 \%$ specificity in relation to human sera control $[23 \cdot \bullet]$.

Although antigen detection has some important advantages over antibody detection in the diagnosis of PCM, particularly in immunocompromised individuals [18, 25, 42], there remains considerable scope for improvement in the area of antigen detection since the last important contributions to this field were made in 2011.

\section{Molecular Methods for Paracoccidioidomycosis Diagnosis}

Nucleic acid-based assays have a good potential to complement and enhance the sensitivity and rapidity of conventional methods used in diagnostic mycology [43]. The majority of molecular tests are polymerase chain reaction (PCR) methods based on the amplification of the fungal gene sequences, and the ribosomal DNA gene was the main target applied in the early scientific work described in the literature [44, 45].

The reliability of the internal transcribed spacer (ITS) region for molecular detection of $P$. brasiliensis was also demonstrated in a real-time PCR [46, 47], being a sensitive methodology for rapid diagnosis of PCM. Recently, this methodology was adapted for a classic PCR format, using P. lutzii instead of $P$. brasiliensis. Despite its high sensitivity $(1.1 \mathrm{pg}$ DNA) and specificity in detecting $P$. lutzii DNA from fungal cultures, this format was not suitable for DNA detection in serum samples, and its utility in other types of clinical samples such as biopsies needs to be further evaluated [48]. Also, a semi-nested PCR with primers ITS1 and ITS4 in the first reaction and MJ03 and ITS1 in the second reaction [49] presented high sensitivity and specificity for detection of P. brasiliensis in tissue. The ITS1-5.8S-ITS2 region of ribosomal RNA was also applied in a nested PCR in a collection of aerosol samples as an optional methodology for environmental detection of Paracoccidioides spp. The molecular detection proved the best method for discovering these fungi in the environment when compared with culturing strategies [50]. 
After molecular characterization of the antigen gp43, the majority of the PCR assays for the diagnosis of PCM were based on oligonucleotide primers derived from the sequence of the gene encoding the gp43 antigen. Several formats of PCR were developed prior to 2011 for detection of P. brasiliensis in biological specimens, such as conventional PCR [51], nested PCR assays [52-55], and semi-nested PCR [49], presenting good sensitivity and specificity.

The gp43 sequence was also the target of a $5^{\prime}$ nuclease assay using fluorescent probes that was found to be straightforward, sensitive, and reproducible for $P$. brasiliensis detection [56]. This sequence was further shown to be useful in the characterization of atypical P. brasiliensis strains [57].

In the last decade the potential diagnostic application of a heminested PCR targeting a new molecular P. brasiliensis marker named ceja- 1 was also evaluated. This methodology was able selectively to detect only DNA from virulent $P$. brasiliensis strains. Non-virulent $P$. brasiliensis strains and other organisms, including several pathogenic systemic fungi, mycobacteria, protozoa, nematodes, mouse and human DNA, were unable to generate amplicons with this protocol. Moreover, the feasibility of this method in specimens from PCM patients was demonstrated, although a large number of clinical samples should be further evaluated for the establishment of sensitivity of this test [58].

\section{Molecular Typing}

P. brasiliensis has shown extensive genetic variability as determined by molecular tools such as restriction fragment length polymorphism (RFLP) analysis [59], electrophoretic karyotyping [60], random amplified polymorphic DNA (RAPD) [61, 62], and microsatellites [63].

The pathogenic fungus $P$. brasiliensis from geographically separated regions of South America was probed by RFLP using Hinfl and HincII, showing clear RFLP patterns. Computational analysis of the RFLP patterns for the 32 isolates suggested that at least five groups of strains existed that were geographically distinct and corresponded closely with present country borders [59].

P. brasiliensis typed by RAPD presented marked differences in its virulence patterns [61]. The ability of P. brasiliensis isolates to invade tissues was studied in an experimental model using susceptible B10.A mice. The analysis was performed according to the severity of the lesions, including the number and size of granuloma, and the number and dissemination of fungi to different organs. Another relevant example of RAPD performance was the results of the analysis of the complex RAPD profiles carried out using humans isolates with three arbitrary primers. The methodology demonstrated limited intraspecific genomic variations in P. brasiliensis isolates, indicating that such methodology could be useful for the analysis of the $P$. brasiliensis genome for characterization or differentiation within this genus [62].

The electrophoretic pattern of contour-clamped homogeneous electric field gel electrophoresis (CHEF) applied to 12 environmental isolates of $P$. brasiliensis has shown five bands, with molecular sizes ranging from 3.2 to $10 \mathrm{Mb}$, and a similar model previously tested and used the clinical isolates as controls. However, one of the bands in the environmental isolates had a lesser weight $(7.2 \mathrm{Mb})$ than the one corresponding to the clinical isolate $(8.8 \mathrm{Mb})$, resulting in a smaller genome of approximately $29.7 \mathrm{Mb}$ [60], and indicating the presence of chromosome polymorphism in this fungus.

Despite the number of available molecular methods developed for strain typing and characterization, they have not been useful for assigning isolates to the described species, thus emphasizing the need for molecular markers capable of distinguishing genetically isolated groups. A PCR- and sequencing-based microsatellite marker system that is easy to perform, stable, adaptable to large numbers of isolates, and discriminatory enough to be used as a typing system in identifying the three proposed phylogenetic species of $P$. brasiliensis was evaluated. This technique was shown to be an unambiguous tool for strain discrimination between two (S1 and PS2) of the cryptic species [2]. Subsequently, genotyping was performed on ten paraffin Paracoccidioidesembedded tissue samples by a nested PCR based on the polymorphism of the gene encoding the gp43 and provided good correlation of histopathological findings with genotypes [63].

\section{Molecular Phylogenetics and the Paracoccidioides brasiliensis Species Complex}

P. brasiliensis contains several different cryptic species, as stated in phylogenetic studies using Multi-Locus Sequence Type (MLST) [2, 3], microsatellite analysis [64], and PRP8 intein sequencing [65].

P. brasiliensis isolates from the Brazilian Central Region showed a significant genetic divergence when compared with other S1, PS2, and PS3 isolates in MLST [3]. This phylogenetic analysis was investigated for coding and non-coding regions from various genes (CHS4, Actin, ODC, URA3, CHS2, HSP70, FKS1, Hydrophobin, Kex1, Catalase A, Catalase P, Formamidase, Glyoxalase) and the ITS sequences of seven new and 14 known isolates of $P$. brasiliensis showing a significant genetic distance between $\mathrm{Pb} 01$ and the remaining genetic groups [3], suggesting the existence of cryptic species of $P$. brasiliensis [2, 3]. Subsequently, the genealogical concordance method of phylogenetic species recognition (GCPSR) identified a clade of 17 genotypically similar isolates, including $\mathrm{Pb} 01$, which are distinct from the S1/PS2/P3 clade. The authors, based on the results obtained with 
GCPSR, considered the "Pb01-like" group to be a new phylogenetic species, and proposed a new species called Paracoccidioides lutzii [4••].

Subsequently, an additional molecular marker, the PRP8 intein, was used to recognize $P$. brasiliensis isolates of the different genetic groups [65]. PRP8 inteins of 22 P. brasiliensis isolates belonging to all four cryptic species were sequenced. Phylogenetic analysis clearly separated the isolates from the four species and revealed a significant difference between $\mathrm{Pb} 01$-like and the remaining species [65]. More recently, the same group concluded that single nucleotide polymorphism analysis of $g p 43, A R F$, and PRP8 intein genes is useful to distinguish among the four cryptic species of the genus Paracoccidioides [66••]. Subsequently, the same authors also demonstrated that nested PCR amplicons from the ITS region from most environmental aerosol samples presented $100 \%$ similarity to $P$. lutzii, showing that this species may occur in southeastern Brazil. Therefore, the development of molecular techniques should not only detect Paracoccidiodes spp. in soil, but also distinguish the isolate in relation to species [50].

\section{Conclusions}

PCM results from infection by Paracoccidioides spp., and continues to cause significant morbidity and mortality, especially in some specific regions of the world. The diagnosis of PCM is classically achieved by a correlation of clinical, epidemiological, and laboratory data. Considerable advances have been made in non-culture-based diagnosis of this systemic mycosis with the development of a variety of methods for the detection of antibodies, antigens, and nucleic acids. The methods described for the diagnosis of PCM each have their strengths and weaknesses and require critical analysis by microbiologists and clinicians. However, not all of the tests described are universally available, which complicates the capacity to diagnose and treat individuals with PCM. In addition, the immunological status of the patient and manifestation of the disease influence the efficacy of the diagnostic test. Continuing efforts to improve or develop diagnostic tests will facilitate our diagnostic capacity. However, such assays will require validation in populations from diverse regions of the world prior to their general application in routine diagnosis. Results obtained from a panel of serologic diagnostic tests play an important role in the diagnosis of PCM. Nevertheless, nucleotide probes specific for the Paracoccidioides species complex, and DNA amplification procedures such as PCR, allow more rapid and precise diagnosis, which would lead to earlier treatment. However, the gold standard for diagnosis continues to be the culture, and the correlation between molecular data and phenotypic characteristics are crucial in identifying the etiological agents of PCM.
Molecular methodologies have also demonstrated several important biological questions related to speciation, mode of reproduction, and genetic population. The basic information obtained from these approaches has implications for the understanding of Paracoccidioides spp. in relation to their behavior and the development of pathogenic features, such as resistance to antimicrobials and virulence factors used for colonization of mammalian hosts. The knowledge obtained from these studies could also be used for the development of innovative diagnostic methods, as well as for novel therapeutic approaches and production of vaccines.

Acknowledgments R.M.Z-O is supported in part by CNPq 350338/ 2000-0 and FAPERJ E-26/103.157/2011.

\section{Compliance with Ethics Guidelines}

Conflict of Interest Rosely Maria Zancope-Oliveira, Claudia Vera Pizzini, Mauro de Medeiros Muniz, Antonio Carlos Francesconi do Valle, and Rodrigo de Almeida-Paes declare that they have no conflict of interest

Human and Animal Rights and Informed Consent This article does not contain any studies with human or animal subjects performed by any of the authors.

\section{References}

Papers of particular interest, published recently, have been highlighted as:

- Of importance

.- Of major importance

1. San-Blas G, Nino-Vega G, Iturriaga T. Paracoccidioides brasiliensis and paracoccidioidomycosis: molecular approaches to morphogenesis, diagnosis, epidemiology, taxonomy and genetics. Med Mycol. 2002;40:225-42.

2. Matute DR, McEwen JG, Puccia R, et al. Cryptic speciation and recombination in the fungus Paracoccidioides brasiliensis as revealed by gene genealogies. Mol Biol Evol. 2006;23:65-73.

3. Carrero LL, Niño-Vega G, Teixeira MM, et al. New Paracoccidioides brasiliensis isolate reveals unexpected genomic variability in this human pathogen. Fungal Genet Biol. 2008;45: 605-12.

4.• Teixeira MM, Theodoro RC, Carvalho MJ, et al. Phylogenetic analysis reveals a high level of speciation in the Paracoccidioides genus. Mol Phylogenet Evol. 2009;52:273-83. A new species, Paracoccidioides lutzii, is proposed based on phylogenetic analysis.

5. Colombo AL, Tobón A, Restrepo A, et al. Epidemiology of endemic systemic fungal infections in Latin America. Med Mycol. 2011;49:785-98.

6. Buitrago MJ, Cuenca-Estrella M. Epidemiologia actual y diagnóstico de laboratório de las micosis endêmicas em España. Enferm Infecc Microbiol Clin. 2012;30:407-13.

7. Martinez R. Paracoccidioidomycosis: the dimension of the problem of a neglected disease. Re Soc Bras Med Trop. 2010;43:480. 
8. Ramos-e-Silva M, Saraiva LES. Paracoccidioidomycosis. Dermatol Clin. 2008;26:257-69.

9. Moreto TC, Marques MEA, Oliveira MLSC, et al. Accuracy of routine diagnostic tests used in paracoccidioidomycosis patients at a university hospital. Trans R Trop Med Hyg. 2011;105:473-8.

10. Marques SA. Paracoccidioidomycosis. Clin Dermatol. 2012;30: $610-5$.

11. Queiroz-Telles F, Escussiato DL. Pulmonary paracoccidioidomycosis. Semin Respir Crit Care Med. 2011;32:764-74.

12. Wanke B, Aide MA. Paracoccidioidomycosis. J Bras Pneumol. 2009;35:1245-9.

13. Moraes AML, Almeida-Paes R, Holanda VL. Micologia. In: Molinaro E, Caputo L, Amendoeira R, editors. Conceitos e métodos para formação de profissionais em laboratórios de saúde. Assis: Triunfal Gráfica e Editora; 2010. p. 399-496. ISBN 978-8598768-41-0.

14. Larone DH. Medically important fungi: a guide to identification. 4th ed. Washington, DC: ASM Press; 2002. ISBN 1-55581-172-8.

15. Bonifaz A, Vázquez-González D, Perusquía-Ortiz AM. Endemic systemic mycoses: coccidioidomycosis, histoplasmosis, paracoccidioidomycosis and blastomycosis. J Dtsch Dermatol Ges. 2011;9:705-14.

16. Ameen M, Talhari C, Talhari S. Advances in paracoccidioidomycosis. Clin Dermatol. 2009;35:576-80.

17. Kwon-Chung KJ, Bennett JE. Medical mycology. Malvern: Lea \& Febiger; 1992. ISBN 0-8122-1463-9.

18. Teles FR, Martins ML. Laboratorial diagnosis of paracoccidioidomycosis and new insights for the future of fungal diagnosis. Talanta. 2011;85:2254-64.

19. Teixeira MM, Theodoro RC, Oliveira FFM, et al.: Paracoccidioides lutzii sp. nov.: biological and clinical implications. Med Mycol. Epub 2013 Jun 14.

20. Cruz RC, Werneck SMC, Oliveira CS, et al. Influence of different media, incubation times, and temperatures for determining the MICs of seven antifungal agents against Paracoccidioides brasiliensis by microdilution. J Clin Microbiol. 2013;51:436-43. A proposal for a microdilution test for P. brasiliensis susceptibility testing against important drugs used in the treatment of paracoccidioidomycosis is presented and a high percentage of susceptible isolates were found under the several experimental conditions used.

21. Marques-da-Silva SH, Colombo AL, Blotta MHSL, et al. Diagnosis of paracoccidioidomycosis by detection of antigen and antibody in bronchoalveolar lavage fluids. Clin Vac Immunol. 2006;13:1363-6.

22. Silveira-Gomes F, Sarmento DN, Pinto TM, et al. Development and evaluation of latex agglutination test for the serodiagnosis of paracoccidioidomycosis. Clin Vac Immunol. 2011;18:604-8.

23.• Caldini CP, Xander P, Kioshima ES, et al. Synthetic peptides mimic gp75 from Paracoccidioides brasiliensis in the diagnosis of paracoccidioidomycosis. Mycopathologia. 2012;174:1-10. P2 peptide that represents a mimotope of gp 75 is a potential tool for the immunodiagnosis of paracoccidioidomycosis.

24. Moses A. Fixação de complemento na blastomicose. Mem Inst Oswaldo Cruz. 1916;8:68-70.

25. Camargo ZP. Serology of paracoccidioidomycosis. Mycopathologia. 2008;165:289-302.

26. Fernandes VC, Coitinho JB, Veloso JMR, et al. Combined use of Paracoccidioides brasiliensis $\mathrm{rPb} 27$ and $\mathrm{rPb} 40$ antigens in an enzyme-linked immunosorbent assay for immunodiagnosis of paracoccidioidomycosis. J Immunol Methods. 2011;367:78-84. The use of combined recombinant antigens in an ELISA provided an excellent assay with high sensitivity and specificity for the immunodiagnosis of paracoccidioidomycosis.

27. Belissimo-Rodrigues F, Vitali LH, Martinez R. Serological diagnosis of paracoccidioidomycosis in HIV-coinfected patients. Mem Inst Oswaldo Cruz. 2010;105:904-7.
28. Belissimo-Rodrigues F, Machado AA, Martinez R. Paracoccidioidomycosis epidemiological features of a 1,000-cases series from a hyperendemic area of Southeast of Brazil. Am J Trop Med Hyg. 2011;85:546-50.

29. Perenha-Viana MCZ, Gonzales IAA, Brockelt SR, et al. Serological diagnosis of paracoccidioidomycosis through a western blot technique. Clin Vac Immunol. 2012;19:616-9.

30.• Machado GC, Moris DV, Arantes TD, et al. Cryptic species of Paracoccidioides brasiliensis: impact on paracoccidioidomycosis immunodiagnosis. Mem Inst Oswaldo Cruz. 2013;108:637-43. The speciation within Paracoccidioides brasiliensisis is important for the serological diagnosis of paracoccidioidomycosis.

31. Mendes-Giannini MJS, Bueno JP, Shikanai-Yassuda MA, et al. Antibody response to $43 \mathrm{kDa}$ glycoprotein of Paracoccidioides brasiliensis as a marker for the evaluation of patients under treatment. Am J Trop Med Hyg. 1990;43:200-6.

32. Blotta MHSL, Camargo ZP. Immunological response to cell-free antigens of Paracoccidioides brasiliensisis: relationship with clinical forms of paracoccidioidomycosis. J Clin Microbiol. 1993;31:671-6.

33. Díez S, Gómez BL, Restrepo A, et al. Paracoccidioides brasiliensis 87-kilodalton antigen, a heat shock protein useful in diagnosis: characterization, purification, and detection in biopsy material via immunohistochemistry. J Clin Microbiol. 2002;40:359-65.

34. Cisalpino PS, Puccia R, Yamauchi LM, et al. Cloning, characterization and epitope expression of the major diagnostic antigen of Paracoccidioides brasiliensisis. J Biol Chem. 1996;271:4553-60.

35. McEwen JG, Ortiz BL, Garcia AM, et al. Molecular cloning, nucleotide sequencing, and characterization of a $27 \mathrm{kDa}$ antigenic protein from Paracoccidioides brasiliensisis. Fun Gen Biol. 1996;20:125-31.

36. Ortiz BL, Garcia AM, Restrepo A, et al. Immunological characterization of a recombinant 27-kilodanton antigenic protein from Paracoccidioides brasiliensisis. Clin Diagn Lab Immunol. 1996;3:239241.

37. Ortiz BL, Díez S, Urán ME, Rivas JM, et al. Use of the 27kilodalton recombinant protein from Paracoccidioides brasiliensis in serodiagnosis of paracoccidioidomycosis. Clin Diagn Lab Immunol. 1998;5:826-30.

38. Santos LS, Fernandes VC, Cruz SG, et al. Profile of total IgG, IgG1, $\mathrm{IgG} 2, \mathrm{IgG} 3$ and $\mathrm{IgG} 4$ levels in sera of patients with paracoccidioidomycosis: treatment follow-up using Mexo and $\mathrm{rPb} 27$ as antigen in an ELISA. Mem Inst Oswaldo Cruz. 2012;107:1-10.

39. Cunha DA, Zancopé-Oliveira RM, Sueli M, Felipe S, et al. Heterologous expression, purification, and immunological reactivity of a recombinant HSP60 from Paracoccidioides brasiliensis. Clin Diagn Lab Immunol. 2002;9:374-7.

40. Bisio LC, Silva SP, Pereira IS, et al. A new Paracoccidioides brasiliensis $70-\mathrm{kDa}$ heat shock protein reacts with sera from paracoccidioidomycosis patients. Med Mycol. 2005;43:495-503.

41. Díez S, Gómez BL, McEwen JG, et al. Combined use of Paracoccidioides brasiliensis recombinant 27-kilodalton and purified 87-kilodalton antigens in an enzyme-linked immunosorbent assay for serodiagnosis of paracoccidioidomycosis. J Clin Microbiol. 2003;41:1536-42.

42. Hamilton. Serodiagnosis of histoplasmosis, paracoccidioidomycosis, and penicilliosis marneffei: current status and future trends. Med Mycol. 1998;1998(36):351-64.

43. Chen SCA, Halliday CL, Meyer W. A review of nucleic acid-based diagnostic tests for systemic mycoses with an emphasis on polymerase chain reaction-based assays. Med Mycol. 2002;40:333-57.

44. Sandhu GS, Aleff RA, Kline BC, Lacaz CS. Molecular detection and identification of Paracoccidioides brasiliensis. J Clin Microbiol. 1997;35:1894-6.

45. Motoyama AB, Venancio EJ, Brandão GO, et al. Molecular identification of Paracoccidioides brasiliensis by PCR amplification of ribosomal DNA. J Clin Microbiol. 2000;38:3106-9. 
46. Buitrago MJ, Merino P, Puente S, et al. Utility of real-time PCR for the detection of Paracoccidioides brasiliensis DNA in the diagnosis of imported paracoccidioidomycosis. Med Mycol. 2009;47:879-82.

47. Buitrago MJ, Bernal-Martinez L, Castelli MV, et al. Histoplasmosis and paracoccidioidomycosis in a non-endemic area: a review of cases and diagnosis. J Travel Med. 2011;18:26-33.

48. Dias L, Carvalho LF, Romano CC. Application of PCR in serum samples for diagnosis of paracoccidioidomycosis in the Southern Bahia-Brazil. PLoS Neg Trop Dis. 2012;6:e1909.

49. Koishi AC, Vituri DF, Donizio Filho PS, et al. A semi-nested PCR assay for molecular detection of Paracoccidioides brasiliensis in tissue samples. Rev Soc Bras Med Trop. 2010;43:728-30.

50. Arantes TD, Theodoro RC, Macoris SAG, Bagagli E. Detection of Paracoccidioides spp. in environmental aerosol samples. Med Mycol. 2013;51:83-92.

51. Gomes GM, Cisalpino PS, Taborda CP, et al. PCR for diagnosis of paracoccidiodomycosis. J Clin Microbiol. 2000;38:3478-80.

52. Bialek R, Ibricevic A, Aepinus C, et al. Detection of Paracoccidioides brasiliensis in tissue samples by a nested PCR assay. J Clin Microbiol. 2000;38:2940-2.

53. Sano A, Yokoyama K, Tamura M, et al. Detection of gp43 and ITS1-5.8S-ITS2 ribosomal RNA genes for Paracoccidioides brasiliensis in paraffin-embedded tissue. Nihon Ishinkin Gakkai Zasshi. 2001;42:23-7.

54. Charbel CE, Levi JE, Martins JE. Evaluation of polymerase chain reaction for the detection of Paracoccidioides brasiliensis DNA on serum samples from patients with paracoccidioidomycosis. Mem Inst Oswaldo Cruz. 2006;101:229-2.

55. Ricci G, Da Silva ID, Borra RC. Detection of Paracoccidioides brasiliensis by PCR in biopsies from patients with paracoccidioidomycosis: correlation with the histopathological pattern. Pathologica. 2007;99:41-5.

56. Semighini CP, Camargo ZP, Puccia R, Goldman MHS, Goldman GH. Molecular identification of Paracoccidioides brasiliensis by $5^{\prime}$ nuclease assay. Diagn Microbiol Infect Dis. 2002;44:383-6.
57. Borba CM, Vinhas EAL, Lopes-Bezerra LM, Lucena-Silva N. Morphological, biochemical and molecular approaches for comparing typical and atypical Paracoccidioides brasiliensis strains. Antonie van Leeuwenhoek. 2005;88:257-66.

58. Correia J, Borba CM, Reis B, et al. The ceja-1 sequence as a potential new molecular marker for Paracoccidioides brasiliensis infection. Mycoses. 2009;53:130-7.

59. Nino-Vega GA, Calcagno AM, San-Blas G, et al. RFLP analysis reveals marked geographical isolation between strains of Paracoccidioides brasiliensis. Med Mycol. 2000;38:437-41.

60. Montoya AE, Alvarez AL, Moreno MN, Restrepo A, McEwen JG. Electrophoretic karyotype of environmental isolates of Paracoccidioides brasiliensis. Med Mycol. 1999;37:229-22.

61. Molinari-Madlum EE, Felipe MS, Soares CMA. Virulence of Paracoccidioides brasiliensis isolates can be correlated to groups defined by random amplified polymorphic DNA analysis. Med Mycol. 1999;37:269-76.

62. Totti DO, Romanha AJ, Grisard EC, Simpson AJ, Koury MC. Random amplified polymorphic DNA (RAPD) analysis of Paracoccidioides brasiliensis isolates. Rev Latinoam Microbiol. 1999;41:139-43.

63. Ricci G, Zelck U, Mota F, et al. Genotyping of Paracoccidioides brasiliensis directly from paraffin embedded tissue. Med Mycol. 2008;46:31-4.

64. Matute DR, Sepulveda VE, Quesada LM, et al. Microsatellite analysis of three phylogenetic species of Paracoccidioides brasiliensis. J Clin Microbiol. 2006;44:2253-7.

65. Theodoro RC, Bagagli E, Oliveira C. Phylogenetic analysis of PRP8 intein in Paracoccidioides brasiliensis species complex. Fungal Genet Biol. 2008;45:1284-91.

66.• Theodoro RC, Teixeira MM, Felipe MSS, et al. Genus Paracoccidioides: species recognition and biogeographic aspects. PLoS One. 2012;7:e37694. This work presents a theory on how this fungus diverged in South America, thus elucidating some evolutionary aspects of this genus. 